\title{
Female Issue of Obtaining Employment in China Relocated Villages: The Case of Loufan County
}

\author{
Xin Yin ${ }^{1, a}$ \\ ${ }^{1}$ Loufan Human Resource and Security Office, Loufan, Taiyuan, Shanxi 030300, China \\ ayinxin1124@163.com
}

\begin{abstract}
This paper focuses on analyzing the factors affecting female employment assistance work in China relocated villages, Loufan County, Taiyuan, in Shanxi Province take as an example, which was a national poverty-stricken county. China has 9.6 million people relocated for liberating from poverty, and solving the employment problem of women in this population is of great significance to consolidate the poverty alleviation achievements and improve the overall situation of women social status. This paper uses qualitative analysis and literature search methods. This paper has two sections. The first part will analyze the factors that affect the employment of women in relocated villages in China and analyze the underlying cultural, historical, social and group individual reasons. The second part will explore the difficulties of helping women in China relocated villages to find employment and related causes.
\end{abstract}

Keywords: female employment in rural areas, female liberation, employment in relocated villages, poverty alleviation

\section{INTRODUCTION}

In response to the national poverty alleviation policy, Loufan County has relocated 25 natural villages in 6 towns involving 4105 people from 1672 families. The county promotes the employment of the relocated people and further try to increase their income through the establishment of poverty alleviation workshops, training the workforce, the purchase of public welfare position and other ways [1]. However, in the process of helping with employment, several problems have been identified with the difficulty of employment for women being the most prominent: many rural women do not have a strong desire to start a career and some are even resistant to employment assistance. Due to the specificity of their urban and rural combinations, the employment assistance work for women in relocated villages also has problems and difficulties different from other types of employment assistance work, especially in terms of employment willingness and working ability. The work of helping employment is difficult, and the conversion rate of employment after career training is meager.

Loufan Rural Labor Transfer Employment Skills Training Application Form

\begin{tabular}{|c|c|c|c|c|c|c|c|c|}
\hline mo. & Hame & Gendex & Age & Eaploymenthlinemploysent Certificate Mo. & ID No. & Address & Tel. & Notes \\
\hline 1 & & & & & & & & \\
\hline 2 & & & & & & & & \\
\hline 3 & & & & & & & & \\
\hline 4 & & & & & & & & \\
\hline 5 & & & & & & & & \\
\hline 6 & & & & & & & & \\
\hline 7 & & & & & & & & \\
\hline 8 & & & & & & & & \\
\hline 9 & & & & & & & & \\
\hline 10 & & & & & & & & \\
\hline 11 & & & & & & & & \\
\hline 12 & & & & & & & & \\
\hline
\end{tabular}

Figure 1 Loufan Rural Labor Transfer Employment Skills Training Application Form 


\section{WHY CAREER GUIDANCE FOR FEMALES IN RELOCATED VILLAGES IS DIFFICULT?}

\subsection{Factors affecting female employment in relocated villages}

Influenced by traditional culture, rural areas in northern China have for many years maintained the tradition of men earning money and women assisting in agricultural work mainly to take care of the family. Farm cultivation, whose feature is "men do farm work and women do housework", has had a profound impact on Chinese rural families. According to research, in contemporary China, the surplus labor force in rural areas continuing to shift to non-agricultural industries, the division of labor in rural areas is gradually changing to male labor and female farming, and farm work has become part of women household work [2]. However, rural areas of such a closed and poor county as Loufan are in a transitional stage with men being responsible for both farming and working outside home, women farming and taking care of the family. It is not common for women to work outside home. This pattern has led to an employment perception that reflects in two ways: on the one hand, females believe that women should naturally be "unemployed" and that their main task is to take care of the family; on the other hand, men believe that men earn money and women take care of the family, and in the extreme, they even believe that their wives working outside home is a sign of incompetence themselves that will disgrace them and therefore oppose women to work outside home. This perception has become the top resistance to employment for rural women.

China's rural population has a lower level of education and this made them less competitive in the job market than the urban population of the same age who are generally having higher education level from a holistic point of view. Studies have shown that non-rural household individuals are more likely to attend university than rural household individuals. There are two main reasons: first, high-quality primary education is not evenly distributed, the quality of primary education in rural areas is lower than in urban areas, and rural students "lose at the starting line" and drop out of the college entrance exam competition early; second, rural families have low expectations of academic returns and therefore pay less attention to their children's education than in urban areas, which ultimately results in rural children's educational performance being inferior to that of urban children [3]. Limited education level prevents rural residents from acquiring more vocational skills and higher education, which are necessary factors for competitiveness in the modern workplace and directly determine whether and what kind of job a job seeker can find. Lack of competitiveness makes rural women struggle with employment and experience more frustration on job search, which in turn undermines their confidence and motivation for employment.

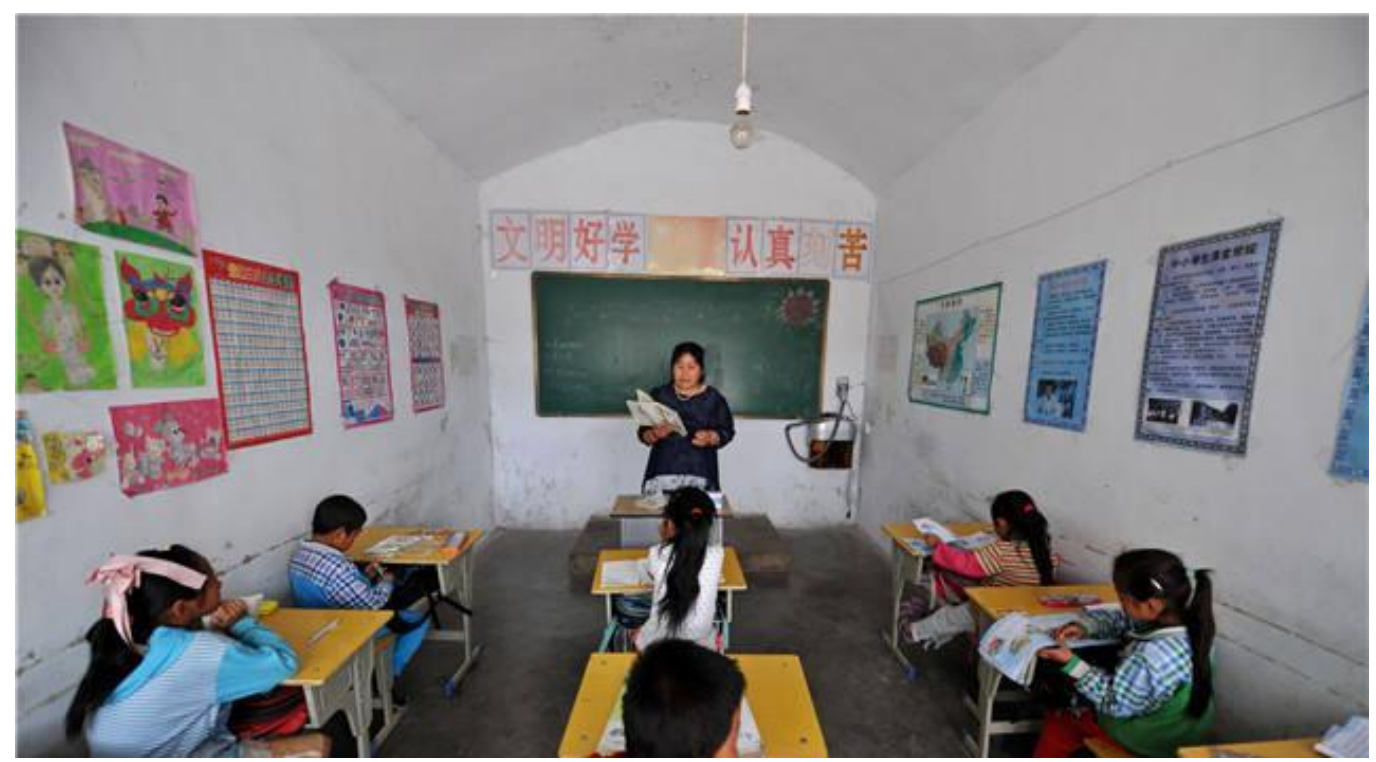

Figure 2 school in rural areas 


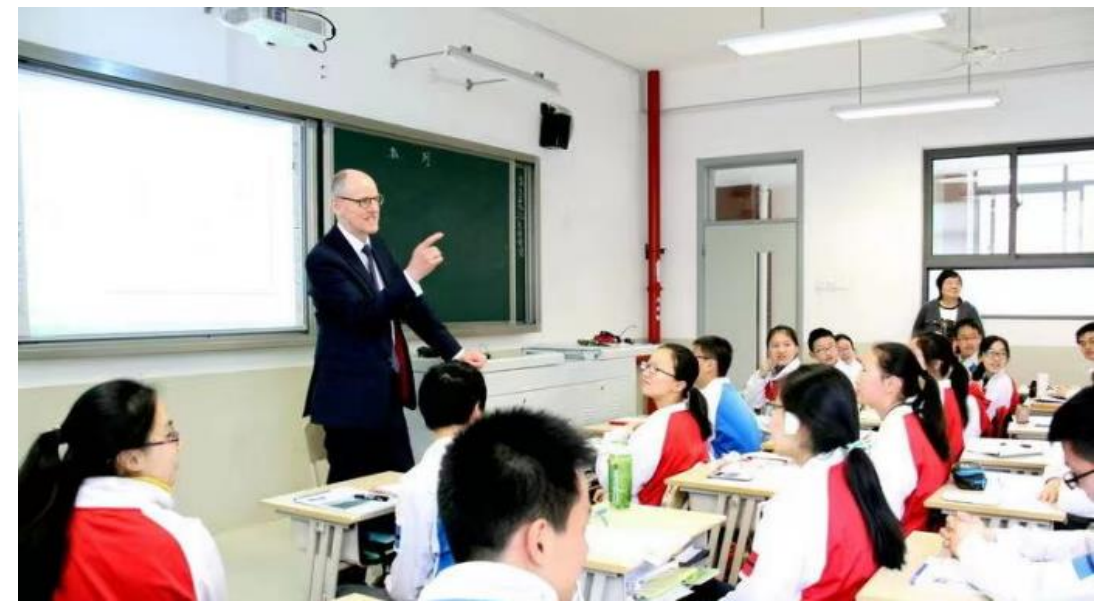

Figure 3 school in Shanghai

Originally, rural people who migrated to other places used to live mainly on farming and crop output, owning the land and being the owners of the means of production themselves, but after migration, the primary household income pattern changed from agricultural income to land rental and working or other income. They are not the productive resource owner any longer. The change in income pattern requires them to readjust to the new production relations, social relations, and social structures that come with it. However, some immigrants are unable to adapt to new social relationships and establish a new way of life because of their age, education level and many other factors. They have a strong discomfort with the bondage that comes with the employment relationship and the fixed rhythm of commuting to work on time.

In addition, the type of training programs offered by the government leads to this result when it comes to low job conversion rates after job training. The current government-provided employment training programs are mainly focused on food and beverage and handicraft industries. However, poor counties like Loufan, with a small population base and a limited market, are unable to absorb large amounts of labor, especially skills of the labor force concentrating on limited industries. This also further discourages other women in relocated villages who have not taken part to career training. This is because they see that even after job training, there are not many employment paths. If the government want to change this situation, the terms of training programs should be enriched, which is a huge test for the government of a county that just overcome poverty.

\subsection{Difficulties in assisting female in relocated villages with obtaining employment}

If rural women choose to go out to work, the first problem they face is that there will be no one to take care of the elderly and children at home, and the rural people's perception is that it is the first duty of women to take care of the elderly and children at home. The People's
Republic of China established women equal status and political rights through the constitution and laws. The emancipation movement of women in the People's Republic of China academically divided into two stages: from 1949 to 1976, Chinese women were liberated as a whole and completed the process of group socialization; after 1977 was mainly a period of the awakening of female consciousness and self consciousness[4]. Rural areas have lagged in the second stage. Thus, although the women liberation in the PRC secured an equal status for Chinese women from the state level, it did not liberate women from the traditional concept of family and the division of labor in the household in folk. Today, not only in rural areas, but also in cities with advanced higher education, a large proportion of people still default to the idea that housework and caring for the elderly and children is the wife's job in the family. This "natural" bondage prevents many women from leaving their families and going to work, especially if their husbands are already working outside the home. If the assistant work does not solve the problem of division of labor within the family, who will do the housework and take care of the elderly and children, it will not help the woman in the family to make the decision to choose to get herself employment. In other words, women will continue to face difficulties working outside the home if men do not participate fully in the family workforce. There is also the option of hiring people to run the household affairs and take care of the elderly and children, which is unrealistic for rural migrant families with insufficient income. Promoting men and women to work outside the home simultaneously, share domestic affairs, and find a balance between home and work requires the combined efforts and cooperation of all sectors of society.

As the rural population is generally less educated, it is difficult to convince them through logical means. This means that the "reasoning" approach does not work well on influencing their ideology. When staffs try to persuade them to attend job training and seek employment by 
explaining the policies, explaining the benefits and emphasizing the significance, they cannot understand the contents well and accept the suggestions easily. Therefore, if the staff wants to work on the ideology of rural women employment, they must deeply understand the life, thinking pattern and value system of rural women, conform to their thinking pattern and evaluation, grasp the parts that rural women and their families care most and start from their vital interests to establish an effective ideological communication platform.

In addition, there are not many women being employed in rural areas. There is a lack of visual examples for rural women to understand the benefits and importance of female career for individual and family both. Most of women in the immigrant villages who are unemployed social with other unemployed women, creating a rigid social circle of unemployed people. In such a group, women can not find good examples to encourage themselves to go out to work but influence each other in the opposite direction, forming an unfavorable comparison of "she does not go out to work, why should I go out to work? If you want me to go out to work, then you should let her do that first". This is also the most frequent response that employment support workers hear when counseling rural women to seek employment. Breaking the social circles and setting positive examples can be a breakthrough for stimulating women in relocated villages to get out of their homes and into the workforce.

\section{CONCLUSION}

There are multiple factors that contribute to the difficulty of employment for rural women. The difficulties of female employment in relocated villages are caused by a combination of historical and social factors and group specificity. From the aspect of people in relocated village, they are trapped by outdated concepts of employment, low level of education and discomfort to the new social environment. These have lead to non-traditional difficulties in the employment assistance work: social attitudes and social conditions that cannot be changed by work of independent agency, communication barriers due to various education levels and the lack of successful examples due to group rigidity. The combination of these factors has led to slow progress and ineffectiveness on employment transfer of rural labor. If relevant departments and staffs want to make a breakthrough in this area, all these hindering factors must be considered one by one and broken one after another, which requires all sectors of the community to effort together including rural women, staffs in employment department, local government and other governmental and social agencies.

\section{REFERENCES}

[1] Bi, J., (2020). Loufan county determine to win the battle against poverty this year. http://paper.tywbw.com/jjxw/c/202005/04/content_181515.htm

[2] Hao, Y., (2012). From male farming and female weaving to male working and female farming: Causes of "feminization of agriculture" - From the perspective of production socialization. Socialism Studies, 202, 82-86

[3] Shao, Y., \& Xu, J. (2017). Higher education expansion and the evolution of inequality of educational opportunity. Economic Perspectives, $12,73-85$

[4] Li, X., (2000). 50 Years, How far have we come? - A review of the liberation and development of Chinese women. Zhejiang Academic Journal, 1, 59-65 